\title{
Incidence and Predictors of Peripheral Venous Catheter-Related Complications in Hospitals in Burkina Faso
}

\author{
Imbe Ignace Yaro1,2, Mikaila Kaboré ${ }^{(\mathbb{D})}$, Martin Lankoande ${ }^{4}$, Farid Belem¹, Ismael Guibla ${ }^{5}$, \\ Ahmed Ouattara1, Charles Ilboudo6, Papougnézambo Bonkoungou ${ }^{4,7}$, \\ Kongnimissom Apoline Sondo ${ }^{4}$, Raweleguinbasba Armel Flavien Kaborée, \\ Nazinigouba Ouedraogo ${ }^{4,6}$
}

\author{
${ }^{1}$ Medical Emergency Department, Yalgado Ouédraogo Teaching Hospital, Ouagadougou, Burkina Faso \\ ${ }^{2}$ Anesthesia, Resuscitation Ward, Regional Hospital of Ziniaré, Ziniaré, Burkina Faso \\ ${ }^{3}$ Infectious Diseases Department, Yalgado Ouédraogo Teaching Hospital, Ouagadougou, Burkina Faso \\ ${ }^{4}$ Health Sciences Training and Research Unit, Joseph KI-Zerbo University, Ouagadougou, Burkina Faso \\ ${ }^{5}$ Anesthesia Resuscitation Department, Sanon Souro Teaching Hospital, Bobo-Dioulasso, Burkina Faso \\ ${ }^{6}$ Anesthesia, Resuscitation and Emergency Department, Yalgado Ouédraogo Teaching Hospital, Ouagadougou, Burkina Faso \\ ${ }^{7}$ Anesthesia, Resuscitation and Emergency Department, Tengandogo Teaching Hospital, Ouagadougou, Burkina Faso \\ Email: y.imbe@yahoo.fr
}

How to cite this paper: Yaro, I.I., Kaboré, M., Lankoande, M., Belem, F., Guibla, I., Ouattara, A., Ilboudo, C., Bonkoungou, P., Sondo, K.A., Kaboré, R.A.F. and Ouedraogo, N. (2021) Incidence and Predictors of Peripheral Venous Catheter-Related Complications in Hospitals in Burkina Faso. Open Journal of Emergency Medicine, 9, 196-208.

https://doi.org/10.4236/ojem.2021.94020

Received: October 25, 2021

Accepted: December 7, 2021

Published: December 10, 2021

Copyright $\odot 2021$ by author(s) and Scientific Research Publishing Inc. This work is licensed under the Creative Commons Attribution International License (CC BY 4.0).

http://creativecommons.org/licenses/by/4.0/ (c) (i) Open Access

\section{Abstract}

Introduction: Peripheral venous catheters (PVCs) are the most commonly used medical devices in hospitals for the administration of medications. Their use can lead to complications of varying severity. Objective: Determine the incidence and factors associated with the occurrence of PVC-related complications. Methods: This was a two-month prospective observational study conducted in the Medical Emergency Department (MED) of Yalgado Ouedraogo Teaching Hospital in Ouagadougou. All patients admitted during the study period who had a PVC inserted and removed were included in the study. Logistic regression analysis was used to identify the factors associated with the occurrence of complications. Results: In total, 459 PVCs were inserted and removed in 415 patients hospitalized at the Medical Emergency Department during the study period. The placement of $37.7 \%(n=173)$ of PVCs resulted in complications in 131 patients (31.6\%). For 644.3 days of catheterization, the incidence density was estimated at 6.5 complications per 1000 patient days. Phlebitis (24.0\%), infection (5.7\%), and accidental removal (2.8\%) were the most frequently identified complications. The average age of the patients was $46.8 \pm 18.9$ years with a sex ratio of 1.22 . The average patient hospitalization duration was $2.5 \pm 2.6$ days. In multivariate analysis, the fac-
\end{abstract}


tors significantly associated with the occurrence of complications after PVC insertion were patient's state of agitation during the procedure $(\mathrm{aOR}=12.59$; $95 \% \mathrm{CI}=4.12-38.49)$, placement of the PVC at the elbow bend $(\mathrm{aOR}=2.17$; $95 \% \mathrm{CI}=1.86-5.52)$, multiple attempts $(\mathrm{aOR}=3.18 ; 95 \% \mathrm{CI}=1.49-6.75)$, administration of $10 \%$ hypertonic glucose solution $(\mathrm{aOR}=3.67 ; 95 \% \mathrm{CI}=$ $1.62-8.33)$, and duration of catheterization beyond 72 hours without being changed $(\mathrm{aOR}=33.00 ; 95 \% \mathrm{CI}=14.19-76.75)$. Conclusion: The incidence of PVC-related complications was relatively high. The identification of the factors that can lead to these complications is relevant to the delivery of quality healthcare to patients.

\section{Keywords}

Peripheral Venous Catheter, Complications, Risk Factors, Emergencies

\section{Introduction}

PVC insertion is one of the most common health care procedures [1]. Thirty to $80 \%$ of patients admitted to hospital will have at least one PVC placed during their hospitalization [2]. It is usually performed for diagnostic or therapeutic purposes [1]. The most common indication is to allow the administration of IV medications and fluids other therapies such as blood products directly into a peripheral vein [3]. Peripheral venous catheterization consists of the introduction of a short catheter of less than $80 \mathrm{~mm}$ in length into the venous system by the transcutaneous route and for a limited period of time. In France, the annual number of PVCs inserted is estimated at 25 million [4]. However, this is not a banal procedure, as it may expose patients to complications that lead to increased morbidity, mortality and prolonged hospitalization [1] [2] [5]. The definition of PVC-related complications is variable from one study to another, resulting in variable incidences of $10 \%$ to $80 \%$ [6] [7]. The main complications are phlebitis [7] [8], occlusion, oozing, accidental removal, and PVC site infection [7] [9] [10] [11]. The latter is one of the most severe complications in terms of mortality and expenses [9]. PVC-related infections, whether local or systemic, are one of the three leading causes of nosocomial infections [1] [12]. Staphylococcus aureus bacteriemia is one of the most severe PVC-related complications in hospitals [13]. Many studies have investigated the risk factors for complications and especially the factors associated with the occurrence of PVC-related infections and phlebitis in various work settings [5] [7] [8] [9] [11] [12]. Few studies have focused on assessing risk factors for all PVC-related complications [14], and even fewer in an emergency care unit.

The investigation of these factors is part of the efforts to promote the quality of care in hospitals. Our aim was to estimate the incidence of complications and to identify the factors associated with their occurrence in a high-density work environment for caregivers, such as emergency departments. 


\section{Patients and Methods}

\subsection{Study Area and Period}

We conducted a prospective observational study over two months from June 15 to August 16, 2015. It was conducted in the Medical Emergency Department of Yalgado Ouedraogo Teaching Hospital in Ouagadougou. This department receives and manages medical emergency cases. It is divided into functional areas with a reception area of eight examination cubicles, an intensive care area of two beds and a short-term hospitalization unit of 20 beds distributed in four rooms.

\subsection{Study Population}

We made a systematic recruitment of all patients with peripheral venous catheters (PVCs) implanted and removed in the medical emergency department during the study period. In order to be able to observe the modalities of catheter placement, all patients with PVCs placed outside medical emergency department were not included. Similarly, patients whose PVC removal was not performed within the medical emergency department were not included in the study, in order to better capture certain complications. Finally, patients with skin lesions at the PVC insertion sites were not included.

\subsection{Study Process}

Data collection was performed 24 hours a day by four trained investigators organized into two teams headed by a principal investigator. Inclusion and data collection began at the time of indication for PVC placement. After informed consent, patient socio-demographic and clinical data were obtained by a case history from the patients and/or their caregivers and by medical record review. Data on catheter placement and on the operator were collected by direct observation of the operator followed by an interview after obtaining his consent. Information on the monitoring and removal of PVCs was obtained by direct examination of the patient, supplemented by an interview with the care team and the medical records review. Data collection ended with the removal of the PVC in the medical emergency department.

\subsection{Study Variables}

The following characteristics were collected by the investigators:

- Patient data: age, gender, level of patient cooperation, comorbidities, diagnosis at admission;

- PVC details, insertion and removal conditions: catheter diameter, indications for PVC insertion, duration of catheterization, operator category, number of attempts, insertion site, nature of fluids and drugs administered through the PVC, place of insertion;

- Monitoring data: events (phlebitis, infection, fluid leakage, obstruction, accidental removal, and pullout);

Operational definitions: 
- Infection: was suspected based on the presence of at least two of the following clinical signs: pain, swelling, redness, presence of pus. Temperature was not taken into account due to the frequent use of analgesics/antipyretics in the department. The culture of the catheter tip was performed in laboratory for bacteriological confirmation [4]. The infection may be local or systemic:

- Phlebitis: was defined as the presence of at least two of the following clinical signs: induration or swelling, redness, pain or palpable venous cord [6] [11] [14] [15].

- Extravasation: was defined as the appearance of edema adjacent to the PVC insertion site causing the perfusion flow to slow down or stop, without inflammatory signs [14].

- Accidental removal: was defined as the unintentional removal of the PVC.

- Pullout: was defined as the removal of the PVC by the patient against medical advice.

\subsection{Statistical Analysis}

Data were entered on EPI Info 3.5.3 software and analyzed using SPSS version 22 software. Analyses were performed in two steps.

By a descriptive method, the mean or median of the quantitative variables were determined according to these variables' distribution curves. For the qualitative variables, a proportion was calculated. The incidence of complications represented the number of events occurring for all patients monitored during 1000 days of exposure to the risk (catheterization). To identify the risk factors for PVC-related complications, we created a dependent variable "complication" that was defined as the occurrence of at least one of the following events in a patient: phlebitis, local or systemic infection, occlusion, fluid leakage, accidental removal, pullout, or extravasation. The explanatory variables were grouped into:

- Socio-demographic factors: age groups, gender;

- Insertion conditions: size, number of attempts, insertion sites, amenities;

- Clinical data: level of patient cooperation;

- Other factors: operator profile, type of IV fluid, duration of catheterization.

Logistic regression analysis was used to identify factors strongly associated with the occurrence of complications in peripheral venous catheterization. The strength of statistical significance was estimated by adjusted odds ratios (aORs) with $95 \%$ confidence intervals (CIs). The significance threshold was set at 0.05 . P-values from statistical analyses were presented as follows: ${ }^{* *}<1 \%$; ${ }^{* *}<1 \%$; $<5 \%$ and (not significant) $>5 \%$.

\subsection{Ethical Aspects}

We got permission from the hospital administration and the head of the department prior to the commencement of the study. Oral consent was obtained from patients before data collection. The anonymity and confidentiality of the data were respected. 


\section{Results}

Out of 1259 admissions during the period, 415 patients (30.9\%) were included. The latter benefited from the installation and removal of 459 PVCs during their stay at Medical Emergency Department. A single patient benefited from the concomitant installation of two PVCs.

\section{Incidence of peripheral venous catheter-related complications}

During the surveillance period, 173 cases of PVC-related complications were recorded, representing $37.7 \%$ of all catheters inserted. The total duration of catheterization in the 415 patients was 644.3 days. Therefore, the incidence density was estimated at 6.5 complications per 1000 patient-days. These complications affected 131 patients (31.5\%). Phlebitis (24\%), infection (5.7\%), and accidental removal $(2.8 \%)$ were the most common complications reported. Peripheral venous catheter-related complications are summarized in Figure 1.

The mean age of the patients was $46.8 \pm 18.9$ years with extremes of 15 and 99 years. The most represented age group was 60 years and over (28.2\%). The sex ratio was 1.22. Patients' diagnoses at entry were grouped by system. Neurological, urogenital, spleen and lymph nodes, and digestive systems were the most affected with $24.3 \%, 21.0 \%, 16.5 \%$, and $13.3 \%$ respectively. Almost half of the patients $(47.2 \%)$ were lying on the floor at the time of PVC placement and in $90.6 \%$ of cases they were conscious and not agitated (Table 1). The average length of patients' hospital stay was $2.5 \pm 2.6$ days (extremes of 0 and 21 days).

Anticipated catheterization (in patients initially stable but whose condition may worsen any time and require intravenous fluids or drugs) (60.7\%) followed by rehydration (33.3\%) were the main reasons for inserting PVC's. In nearly $3 / 4$ of the cases $(73.5 \%)$, PVCs were inserted by the department's permanent nurses. The forearm (33.7\%) and the wrist (32.3\%) were the favorite sites for PVC placement. The catheters were of four sizes: the 22-gauge was the most commonly used (45.5\%), followed by the 20 -gauge (37.6\%). A first attempt to place the PVC was successful in most cases $(89.2 \%)$. Normal saline solution $(0.9 \%$ $\mathrm{NaCl})(45.1 \%)$ and $5 \%$ glucose solution $(41.2 \%)$ were the most common fluids used during catheterization. The PVCs were replaced within 72 hours in $84.6 \%$ of cases. The results are presented in Table 2.

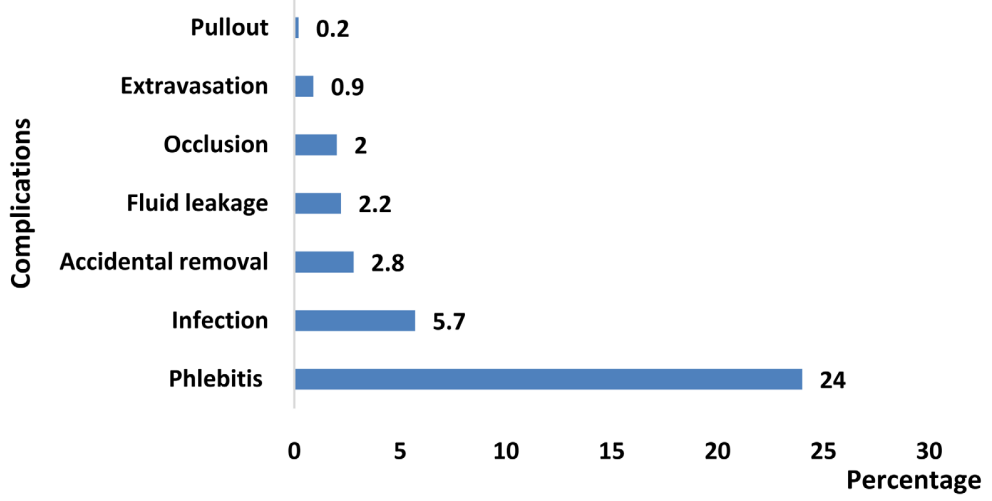

Figure 1. Complications of peripheral venous catheterization. 
Table 1. General characteristics of the sample.

\begin{tabular}{|c|c|c|}
\hline Variables & Numbers (n) & Percentages (\%) \\
\hline \multicolumn{3}{|l|}{ Age groups (years) } \\
\hline$<20$ & 21 & 5.1 \\
\hline $20-30$ & 70 & 16.9 \\
\hline $30-40$ & 74 & 17.8 \\
\hline $40-50$ & 69 & 16.6 \\
\hline $50-60$ & 64 & 15.4 \\
\hline$\geq 60$ & 117 & 28.2 \\
\hline \multicolumn{3}{|l|}{ Gender } \\
\hline Male & 228 & 54.9 \\
\hline Female & 187 & 45.1 \\
\hline \multicolumn{3}{|l|}{ Patient cooperation level } \\
\hline Conscious and calm & 376 & 90.6 \\
\hline Motor restlessness & 22 & 5.3 \\
\hline Coma & 17 & 4.1 \\
\hline \multicolumn{3}{|c|}{ Convenience (place where the patient is settled) } \\
\hline On the floor & 196 & 47.2 \\
\hline On examination table & 177 & 42.7 \\
\hline On a chair & 42 & 10.1 \\
\hline
\end{tabular}

Table 2. Features related to peripheral venous catheters.

\begin{tabular}{ccc}
\hline Variables & Numbers (n) & Percentages (\%) \\
\hline Indications for catheter placement & 252 & 60.7 \\
Anticipated catheterization & 138 & 33.3 \\
Rehydration & 119 & 28.7 \\
Antibiotherapy & 50 & 12.0 \\
Blood transfusion & & \\
Operator's professional category & 305 & 73.5 \\
Registered Nurse & 110 & 26.5 \\
Others & & \\
PVC Insertion Site & 140 & 33.7 \\
Forearm & 134 & 32.3 \\
Wrist & 89 & 21.4 \\
Back of the hand & 40 & 9.6 \\
Elbow bend & & \\
\hline
\end{tabular}




\section{Continued}

Others $^{* *}$

Catheter size (Gauge)

24

22

20

18

Number of insertion attempts

Once

At least twice

Fluids used for catheterization

Normal saline $(0.9 \% \mathrm{NaCl})$

$5 \%$ glucose solution

Ringer Lactate

$10 \%$ hypertonic glucose solution

Duration of catheterization (hours)

$$
<72
$$

$\geq 72$
5.8

45.5

156

37.6

46

370

45

187

45.1

171

41.2

69

16.6

36

8.7

351

84.6

${ }^{\star}$ Other: nurse trainee (70), student trainee (35), physician (5); ${ }^{* *}$ Other: arm (4), back of foot (3), jugular (3), index finger (2).

The level of patient's cooperation during PVC placement $(\mathrm{p}<0.0001)$, PVC insertion site $(\mathrm{p}=0.0001)$, PVC size $(\mathrm{p}=0.048)$, number of attempts before PVC insertion ( $p=0.008$ ), use of $10 \%$ hypertonic glucose solution $(p=0.013)$, and catheterization duration $\geq 72$ before removal ( $\mathrm{p}<0.0001)$ were the factors associated with the occurrence of complications (Table 3 ).

\section{Predictors of peripheral venous catheter-related complications}

We performed a multivariate analysis to identify factors strongly associated with the occurrence of complications after PVC placement. It was found that agitated patients were 13 times more likely to develop complications compared with patients who were calm at the time of PVC insertion (aOR $=12.59$; 95\% CI $=4.12$ - 38.49). In addition, those who were implanted a PVC at the elbow bend were twice more likely to develop complications compared with those who were implanted a PVC at the wrist $(\mathrm{aOR}=2.17 ; 95 \% \mathrm{CI}=1.86-5.52)$. Multiple attempts to place the PVC increased the risk of developing complications by three times $(\mathrm{aOR}=3.18 ; 95 \% \mathrm{CI}=1.49-6.75)$. Administration of $10 \%$ hypertonic glucose solution at the time of PVC insertion doubled the risk of PVC-related complications $(\mathrm{aOR}=3.67 ; 95 \% \mathrm{CI}=1.62-8.33)$. Finally, having the catheter maintained for more than 72 hours without replacement multiplied the risk of developing complications during hospitalization by 33 (aOR $=33.00 ; 95 \% \mathrm{CI}=$ 14.19 - 76.75). These results are presented in Table 4. 
Table 3. Bivariate analysis of predictive factors of PVC.

\begin{tabular}{|c|c|c|c|c|c|}
\hline \multirow{2}{*}{ Variables } & \multirow{2}{*}{ Items } & \multirow{2}{*}{$\begin{array}{c}\text { Number } \\
\mathrm{N}\end{array}$} & \multicolumn{2}{|c|}{ Complications } & \multirow{2}{*}{$\mathrm{p}$} \\
\hline & & & $\mathrm{n}$ & $\%$ & \\
\hline \multirow{3}{*}{$\begin{array}{l}\text { Age of patient } \\
\quad \text { (years) }\end{array}$} & $<30$ & 91 & 22 & 24.2 & \\
\hline & $30-59$ & 207 & 73 & 35.3 & 0.161 \\
\hline & $\geq 60$ & 117 & 36 & 20.8 & \\
\hline \multirow{2}{*}{ Gender } & Male & 228 & 69 & 30.3 & \\
\hline & Female & 187 & 62 & 33.2 & 0.528 \\
\hline \multirow{2}{*}{$\begin{array}{c}\text { Patient cooperation } \\
\text { level }\end{array}$} & Calm & 393 & 114 & 29.0 & \\
\hline & Agitation & 22 & 17 & 77.3 & $<0.0001$ \\
\hline \multirow{5}{*}{ Insertion site of PVC } & Wrist & 134 & 29 & 21.6 & \\
\hline & Back of the hand & 89 & 20 & 22.5 & 0.037 \\
\hline & Forearm & 140 & 59 & 42.1 & 0.118 \\
\hline & Elbow bend & 40 & 17 & 42.5 & 0.001 \\
\hline & Others ${ }^{*}$ & 12 & 6 & 50.0 & 0.163 \\
\hline \multirow{2}{*}{ Type of operator } & Nurse & 305 & 36 & 32.7 & \\
\hline & Others ${ }^{* *}$ & 110 & 95 & 31.1 & 0.760 \\
\hline \multirow{2}{*}{ Job tenure } & $<3$ ans & 321 & 99 & 30.8 & \\
\hline & $\geq 3$ ans & 94 & 32 & 34.0 & 0.557 \\
\hline \multirow{2}{*}{ PVC gauge } & Gauge 18 & 46 & 22 & 47.8 & \\
\hline & Others $^{\star * *}$ & 369 & 109 & 29.5 & 0.048 \\
\hline \multirow{2}{*}{$\begin{array}{l}\text { Number of vein } \\
\text { punctures }\end{array}$} & 1 & 370 & 109 & 29.5 & \\
\hline & $2-3$ & 45 & 22 & 48.9 & 0.008 \\
\hline \multirow{3}{*}{$\begin{array}{l}\text { Infusion solution: } \\
10 \% \text { hypertonic } \\
\text { glucose dextrose }\end{array}$} & No & 379 & 113 & 29.8 & \\
\hline & Yes & 36 & 18 & 50.0 & 0.013 \\
\hline & $\begin{array}{l}\text { Patient on } \\
\text { the floor }\end{array}$ & 196 & 69 & 35.2 & 0.131 \\
\hline \multirow[t]{2}{*}{ Convenience } & On a chair & 42 & 7 & 16.7 & \\
\hline & $\begin{array}{l}\text { On examination } \\
\text { table }\end{array}$ & 177 & 55 & 31.1 & 0.852 \\
\hline \multirow{2}{*}{$\begin{array}{c}\text { Duration of } \\
\text { catheterization }\end{array}$} & $<72$ hours & 351 & 76 & 21.7 & \\
\hline & $\geq 72$ hours & 64 & 55 & 85.9 & $<0.0001$ \\
\hline
\end{tabular}

Significance p: ns (not significant) $\geq 0.05 ;\left(^{*}\right)<0.05 ;\left({ }^{* *}\right)<0.01 ;\left({ }^{* * *}\right)<0.001 .{ }^{*}$ others: arm (4), back of foot (3), jugular (3), index finger (2). ${ }^{\star \star}$ Others: nurse trainee (70), student trainee (35), physician (5). ${ }^{* *}$ Others: Gauge 20, 22 and 24. 
Table 4. Predictive factors for peripheral venous catheterization complications.

\begin{tabular}{|c|c|c|c|c|}
\hline Variables & Non Ajusted OR & $95 \% \mathrm{CI}$ & Ajusted OR & $95 \% \mathrm{CI}$ \\
\hline \multicolumn{5}{|l|}{$\begin{array}{l}\text { Level of patient's } \\
\text { cooperation }\end{array}$} \\
\hline Calm & 1 & & 1 & \\
\hline Coma & $1.02 \mathrm{~ns}$ & $0.35-2.97$ & $1.03 \mathrm{~ns}$ & $0.25-4.25$ \\
\hline Agitation & $8.33^{\star * *}$ & $2.99-23.14$ & $12.59^{* * *}$ & $4.12-38.49$ \\
\hline \multicolumn{5}{|l|}{ PVC insertion site } \\
\hline Wrist & 1 & & 1 & \\
\hline Back of the hand & $1.05 \mathrm{~ns}$ & $0.55-2.00$ & $0.79 \mathrm{~ns}$ & $0.36-1.78$ \\
\hline Forearm & $2.64^{\star}$ & $1.55-4.48$ & $2.07 \mathrm{~ns}$ & $0.89-3.96$ \\
\hline Elbow bend & $2.68^{\star * *}$ & $1.27-5.66$ & $2.17^{\star}$ & $1.86-5.52$ \\
\hline Others $^{*}$ & $3.62^{*}$ & $1.09-12.07$ & $0.61 \mathrm{~ns}$ & $0.12-2.99$ \\
\hline \multicolumn{5}{|l|}{ PVC calibre } \\
\hline 18 Gauge & $1.78^{\star}$ & $1.01-3.34$ & $1.97 \mathrm{~ns}$ & $0.90-4.29$ \\
\hline Others ${ }^{\star *}$ & 1 & & 1 & \\
\hline \multicolumn{5}{|l|}{$\begin{array}{c}\text { Number of } \\
\text { vein punctures }\end{array}$} \\
\hline 1 & 1 & & 1 & \\
\hline $2-3$ & $2.29^{* *}$ & $1.23-4.28$ & $3.18^{\star *}$ & $1.49-6.75$ \\
\hline \multicolumn{4}{|l|}{ Infusion solution: } & $10 \%$ hypertonic glucose \\
\hline No & 1 & & 1 & \\
\hline Yes & $2.35^{\star}$ & $1.18-4.69$ & $3.67^{* *}$ & $1.62-8.33$ \\
\hline \multicolumn{5}{|l|}{$\begin{array}{c}\text { Duration of } \\
\text { catheterization }\end{array}$} \\
\hline$<72$ hours & 1 & & 1 & \\
\hline$\geq 72$ hours & $22.11^{\star * *}$ & $10.45-46.77$ & $33.00^{* * *}$ & $14.19-76.75$ \\
\hline
\end{tabular}

Significance p: ns (not significant) $\geq 0.05 ;\left({ }^{*}\right)<0.05 ;\left({ }^{* *}\right)<0.01 ;\left({ }^{* * *}\right)<0.001 .{ }^{*}$ others: $\operatorname{arm}(4)$, back of foot (3), jugular (3), index finger (2). ${ }^{* \star}$ Others: Gauge 20, 22 and 24.

\section{Discussion}

This study showed that PVC insertion can lead to different types of complications with variable risk factors. One hundred and seventy-three cases of PVCrelated complications were recorded in the study. This accounts for $37.7 \%$ of all catheters inserted and $31.5 \%$ of patients catheterized. The incidence density was estimated at 6.5 complications per 1000 patient-days. A 2014 observational study conducted by Abolfotouh et al. on the predictors of PVC complications showed results in line with our findings, with $32.4 \%$ of catheter-related complications, 
affecting $39.2 \%$ of patients. However, the incidence density reported in their study was 75.84 complications per 1000 catheter-days [14]. The definitions given to PVC-related complications are very different from one study to another, making it often difficult to compare incidences [6] [14]. As shown in other studies [2] [7] [11] [16], phlebitis was the most frequent complication affecting our patients. It stands at the crossroad of mechanical and infectious complications. It mostly causes discomfort to the patient, generally leading to the removal and insertion of a new catheter in another site [15]. The frequency of phlebitis varies from $2 \%$ to $80 \%$ depending on the authors [7] [11] [16]. This study reported a frequency of $24.0 \%$. These significant variations can be explained by methodological differences, particularly phlebitis definition criteria [2] [11] [15] [16]; and by the patient's clinical condition and the catheter insertion site [9] [11].

Skin infection, which is considered to be one of the major PVC-related complications, was observed in $5.7 \%$ of our patients. These localized infections may subsequently disseminate and cause bacteremia. Lee et al. found $13 \%$ of bacteremia complicating PVC-related skin infections in their study [12]. Non-compliance of healthcare professionals with hygiene rules, prolonged maintenance of intravascular catheters without replacement, and the patient's clinical condition are factors that may explain the occurrence of infections in peripheral venous catheterization [12]. In addition to phlebitis and infection, other complications noted in our series and confirmed by literature were accidental withdrawal, extravasation and fluid leakage [8] [14].

Among the factors associated with the occurrence of complications, it was reported that agitated patients had a 13-fold greater risk of developing complications than patients who remained calm during the insertion of the intravascular catheter. This motor agitation is a risk to both caregiver and patient. While it is recommended that PVCs be inserted in the distal part of the upper extremities, such as the hand/wrist or forearm [17], our study found that the insertion of PVCs in the elbow bend was twice as likely to result in complications as the wrist insertion. Our result is in line with those reported by Rego Furtado et al., [11] in a study performed in a surgical unit on the predisposing factors to phlebitis, who highlighted that catheter insertion in the elbow bend seemed to increase the incidence of phlebitis compared with other anatomical regions. This could be explained by the fact that joint movements cause friction between the catheter and the intima of the vein, which in the long-term results in intima injury and the development of phlebitis [11] [15].

Multiple attempts to place the PVC were three times more likely to lead to complications in our patients. The insufficient mastery of PVC insertion techniques by some practitioners in the department could explain this. It is important to set up continuous training on good practices for the staff in order to address this problem and provide better comfort to patients during care. More than half of our patients (58.8\%) received 5\% isotonic glucose solution. However, the administration of $10 \%$ hypertonic glucose solution at the time of PVC 
implantation was twice as likely to cause complications. It is known that certain solutions, due to their $\mathrm{pH}$ or osmolality, can cause damage to peripheral vessels, especially in case of extravasation [11] [15] [17].

Apart from the infusion solution, certain drugs have been cited as risk factors for complications. These include antibiotics such as levofloxacin and azithromycin [8] [11] [15]. They were not specifically used in our study.

About $15.4 \%$ of our patients had a catheter in place for more than 72 hours without being replaced. Maintaining the catheter beyond this time was 22 times more likely to result in complications during hospitalization. This finding was also reported by other authors. Therefore, it is recommended to change the catheter every 72 to 96 hours to avoid complications. The only situation in which the PVC can be maintained beyond 96 hours is when there is a difficulty in implanting the catheter due to the status of the peripheral venous network, associated with the absence of signs of phlebitis. Signs of phlebitis may include heat, pain, erythema and palpable venous cord [17]. On the other hand, some authors consider that the catheter replacement should not be systematic after 72 hours, but should be motivated by a clinical indication in order to reduce the complications due to frequent PVC insertions during hospitalization [14]. However, it is recognized that the expertise of the nurse who inserts the intravenous catheter and who monitors it after insertion plays a major role in preventing complications [8] [9] [15].

Nevertheless, this study had some limitations and biases that should be highlighted:

- It was a single-center study; therefore, the results cannot be extrapolated to all emergency departments. In addition, the study was carried out in an emergency department where the high workload and the rapidity of actions may have contributed to an increased incidence of complications in our study.

- The fact of not performing bacteriological analyses of all the PVCs included in the study makes it difficult to estimate the prevalence and risk factors of infection.

- The fact of not performing venous Doppler echocardiography in case of clinical suspicion of phlebitis to confirm or exclude the occurrence of thrombophlebitis.

\section{Conclusion}

The study concluded that there was a relatively high incidence of complications resulting from the insertion and removal of PVCs. Identifying the factors associated with the occurrence of these complications is necessary for each patient. It would be important to develop and implement good clinical practice recommendations, especially for nurses. These recommendations should ensure proper management of peripheral venous catheters to prevent complications that might cause severe damage to the patient. 


\section{Conflicts of Interest}

The authors declare no conflicts of interest regarding the publication of this paper.

\section{References}

[1] Mer, M. (2006) Intravascular Catheter-Related Infection-Current Concepts. Southern African Journal of Critical Care, 22, 4-12.

[2] Zhang, L., Cao, S., Marsh, N., et al. (2016) Infection Risks Associated with Peripheral Vascular Catheters. Journal of Infection Prevention, 17, 207-213. https://doi.org/10.1177/1757177416655472

[3] Beecham, G.B. and Tackling, G. (2021) Peripheral Line Placement. StatPearls Publishing, Treasure Island. https://www.ncbi.nlm.nih.gov/books/NBK539795/

[4] Haute Autorité de Santé (HAS) and Société Française d'Hygiène Hospitalière (SFHH) (2015) Recommandations pour la pratique clinique. Prévention des infections liées aux cathéters veineux périphériques. https://www.has-sante.fr/

[5] Ghali, H., Rejeb, O.B., Bouafia, N., et al. (2018) Incidence of Adverse Events Associated with the Peripheral Venous Catheter in a Tunisian University Hospital. Santé Publique, 30, 663-669.

[6] Tagalakis, V., Kahn, S.R., Libman, M., et al. (2002) The Epidemiology of Peripheral Vein Infusion Thrombophlebitis: A Critical Review. The American Journal of Medicine, 113, 146-151. https://doi.org/10.1016/S0002-9343(02)01163-4

[7] Barbut, F., Pistone, T., Guiguet, M., et al. (2003) Complications Due to Peripheral Venous Catheterization. Prospective Study. Presse Medicale, 32, 450-456.

[8] Anabela, S., Veiga, P., and Parreira, P. (2011) Incidence of Phlebitis in Patients with Peripheral Intravenous Catheters: The Influence of Some Risk Factors. Australian Journal of Advanced Nursing, 30, 32-39.

[9] Dychter, S.S., Gold, D.A., Carson, D., et al. (2021) Intravenous Therapy: A Review of Complications and Economic Considerations of Peripheral Access. Journal of Infusion Nursing, 35, 84-91. https://doi.org/10.1097/NAN.0b013e31824237ce

[10] Gorski, L.A. (2017) The 2016 Infusion Therapy Standards of Practice. Home Healthcare Now, 35, 10-18. https://doi.org/10.1097/NHH.0000000000000481

[11] do Rego Furtado, L.C. (2011) Incidence and Predisposing Factors of Phlebitis in a Surgery Department. British Journal of Nursing, 20, S16-S25.

https://doi.org/10.12968/bjon.2011.20.Sup7.S16

[12] Lee, W.L., Liao, S.F., Lee, W.C., et al. (2010) Soft Tissue Infections Related to Peripheral Intravenous Catheters in Hospitalized Patients: A Case-Control Study. Journal of Hospital Infection, 76, 124-129. https://doi.org/10.1016/j.jhin.2010.05.012

[13] Haas, L.E.M., Kortlandt, B.C., Thijsen, S.F.T., et al. (2012) A Fatal Complication of A Peripheral Venous Catheter. International Journal of Clinical Medicine, 3, 433-437. https://doi.org/10.4236/ijcm.2012.35081

[14] Abolfotouh, M.A., Salam, M., Bani Mustafa, A., et al. (2009) Prospective Study of Incidence and Predictors of Peripheral Intravenous Catheter-Induced Complications. Therapeutics and Clinical Risk Management, 10, 993-1001. https://doi.org/10.2147/TCRM.S74685

[15] Messika, J., Roux, D., Dreyfuss, D., et al. (2015) Voies veineuses périphériques et risque d'infections acquises en réanimation. Réanimation, 24, 310-317. 
https://doi.org/10.1007/s13546-015-1063-5

[16] Ray-Barruel, G., Polit, D.F., Murfield, J.E., et al. (2014) Infusion Phlebitis Assessment Measures: A Systematic Review. Journal of Evaluation in Clinical Practice, 20, 191-202. https://doi.org/10.1111/jep.12107

[17] Department of Health, Centre for Healthcare Related Infection Surveillance and Prevention \& Tuberculosis Control (2015) Guideline for Peripheral Intravenous Catheters [PIVC]. Queensland Health. https://www.health.qld.gov.au/ 